\title{
Predictors of Pathologic Complete Response Following Neoadjuvant Chemoradiotherapy for Rectal Cancer
}

\author{
Eisar Al-Sukhni, MD, MSc ${ }^{1}$, Kristopher Attwood, PhD $^{2}$, David M. Mattson, MD $^{3}$, Emmanuel \\ Gabriel, MD, PhD ${ }^{1}$, and Steven J. Nurkin, MD, MS ${ }^{1}$ \\ ${ }^{1}$ Department of Surgical Oncology, Roswell Park Cancer Institute, Buffalo, NY \\ ${ }^{2}$ Department of Biostatistics, Roswell Park Cancer Institute, Buffalo, NY \\ ${ }^{3}$ Department of Radiation Medicine, Roswell Park Cancer Institute, Buffalo, NY
}

\begin{abstract}
Background-Some patients with rectal cancer who receive neoadjuvant chemoradiotherapy (nCRT) achieve a pathologic complete response (pCR) and may be eligible for less radical surgery or non-operative management. The aim of this study was to identify variables that predict pCR after nCRT for rectal cancer and to examine the impact of $\mathrm{pCR}$ on postoperative complications.

Methods-A retrospective review was performed of the NCDB from 2006 to 2011. Patients with rectal cancer who received nCRT followed by radical resection were included in this study. Multivariable analysis of the association between clinicopathologic characteristics and $\mathrm{pCR}$ was performed, and propensity-adjusted analysis was used to identify differences in postoperative morbidity between $\mathrm{pCR}$ and non-pCR patients.
\end{abstract}

Results-A total of 23,747 patients were included in the study. Factors associated with pCR included lower tumor grade, lower clinical $\mathrm{T}$ and $\mathrm{N}$ stage, higher radiation dose, and delaying surgery by more than 6- 8 weeks after the end of radiation, while lack of health insurance was linked with a lower likelihood of pCR. Complete response was not associated with an increased risk of major postoperative complications.

Conclusions-Several clinical, pathologic, and treatment variables can help to predict which patients are most likely to have pCR after nCRT for rectal cancer. Awareness of these variables can be valuable in counseling patients regarding prognosis and treatment options.

Neoadjuvant therapy is the current standard of care for locally advanced rectal cancer. In the US, this therapy typically takes the form of concurrent long-course chemoradiation (nCRT). Some patients with rectal cancer who receive nCRT achieve a pathologic complete response (pCR) that is associated with an improved long-term prognosis compared with patients who have residual tumor in the final specimen. ${ }^{1,2}$ Standard surgery for rectal cancer can result in significant morbidity with negative long-term impact on bowel, urinary and sexual function,

E. Al-Sukhni, MD, MSc, eisar.al-sukhni@ roswellpark.org.

DISCLOSURES Eisar Al-Sukhni, Kristopher Attwood, David M. Mattson, Emmanuel Gabriel, and Steven J. Nurkin have no relevant financial relationships to disclose.

The American College of Surgeons Committee on Cancer provided the Participant User File from the NCDB but has not reviewed or validated the results or conclusions of our study. 
and the need for a temporary or permanent ostomy. Over the past decade, there has been increasing interest in 'watchful waiting' as an alternative to radical resection. ${ }^{3-5}$ In this approach, patients who demonstrate a complete clinical response (cCR) following neoadjuvant therapy do not undergo surgery but instead are monitored closely and offered salvage surgery in the event of relapse. ${ }^{6}$ Emerging data suggest that certain low-risk tumors may be appropriate candidates for this strategy. ${ }^{7-11}$ However, it is well established that $\mathrm{cCR}$ does not equate to $\mathrm{pCR}$ as residual tumor may be identified in up to $75 \%$ of resected specimens where the gross tumor has clinically disappeared. ${ }^{12,13}$ Furthermore, even among patients with complete pathologic resolution of the primary tumor, residual nodal disease is present in up to $15 \%$ of cases $^{14,15}$ and is an independent predictor of poor outcomes. ${ }^{16}$ Consequently, it is of clinical interest to identify factors that can predict $\mathrm{pCR}$, both to optimize the likelihood of achieving pCR and to select patients who may potentially avoid surgery after completion of nCRT.

The aim of this study was to identify clinicopathologic and treatment-related variables that predict $\mathrm{pCR}$ after $\mathrm{nCRT}$ for rectal cancer and to examine the impact of $\mathrm{pCR}$ on postoperative complications.

\section{METHODS}

After approval from the Institutional Review Board, the American College of Surgeons' (ACS) National Cancer Database (NCDB) was queried to identify patients from 2006 to 2011 with non-metastatic rectal adenocarcinoma who received nCRT followed by radical surgery. Documentation of several cancer-specific variables (e.g. circumferential resection margin) in the NCDB began at various time points between 2004 and 2010; thus, the study period was chosen to provide the largest sample of rectal cancer patients with the most complete information available in the database at the time the study was conducted. Patients were queried from the rectal cancer Participant User Files (PUF) of the NCDB. For adenocarcinoma, the following International Classification of Diseases (ICD)-O-3 codes were used: 8140-8148, 8200, 8260-8263, and 8480-8496.

Data were collected regarding patient, disease, and treatment variables. Patient variables included age, sex, race, geographic setting, insurance coverage, and comorbidities. Disease variables included year of diagnosis, grade, size, clinical TNM stage, pathologic TNM stage, number of nodes examined, preoperative carcinoembryonic antigen (CEA), presence of tumor deposits, lymphovascular invasion (LVI), perineural invasion (PNI), tumor regression grade, and margin status. Treatment variables included treating facility type, surgical procedure, surgical approach, radiation modality, radiation dose, and interval from end of radiation to surgery.

The main outcome was predictors of $\mathrm{pCR}$, defined as the absence of tumor in the final pathologic specimen (ypT0/x, N0/x). The notation ' $\mathrm{x}$ ' in pathology reports indicates that tumor cannot be assessed in the specimen; among patients with biopsy-proven tumor who then undergo neoadjuvant treatment, it signifies the absence of tumor in the final specimen (and thus a complete response). Additional outcomes were the associations between postoperative complications with pCR. Postoperative length of stay (LOS), 30-day mortality 
and unplanned readmission were used as surrogate indicators for postoperative complications as this variable is not documented in the NCDB.

Patient, disease, and treatment characteristics were reported using the mean, median and range for continuous variables, and frequencies and relative frequencies for categorical variables. The association between response status and patient characteristics were evaluated using the Mann-Whitney $U$ test and Fisher's exact test for continuous and categorical variables, respectively. Factors that may be independently associated with response status were identified using a multivariable logistic regression model and the backwards selection method (alpha exit $=0.05)$.

The association between LOS and response status was examined using a two-sided independent sample $t$ test, where a log-transformation was used to meet assumptions. Analysis of covariance (ANCOVA) was then used to compare LOS between response groups while adjusting, via propensity score, for the significant factors identified in the multivariable model.

The association between response status and both 30-day mortality and unplanned readmission was examined using Fisher's exact test. A stratified logistic regression model, stratified by propensity score, was used to evaluate these associations while adjusting for the factors identified in the multivariable model. Odds ratios and corresponding $95 \%$ confidence intervals were obtained from model estimates.

All analyses were conducted using SAS v9.4 (SAS Institute Inc., Cary, NC, USA) at a significance level of 0.05 .

\section{RESULTS}

A total of 23,747 patients, with a median age of 60 years, met the inclusion criteria. Characteristics of the study cohort are summarized in Table 1 . The vast majority of patients were White, had few or no comorbidities, and had government or private health insurance. Tumors were predominantly moderately differentiated and approximately one-third were larger than $5 \mathrm{~cm}$. Pre-therapy clinical stage was T3-4 in $85 \%$ of patients and node positive in $46.7 \%$ of patients. On final pathology, these proportions decreased to 44.3 and $27.6 \%$, respectively, indicating downstaging in a substantial proportion of the patient cohort. Most patients were treated with external beam therapy at a dose of 4500-5040 cGy, and sphincter preservation was possible in two-thirds of the patients. The interval from the end of radiation to surgery was 6 weeks or longer in $77.2 \%$ of patients.

\section{Factors Associated with Pathologic Complete Response (pCR)}

The proportion of patients with pCR was $23.3 \%$. On multivariable analysis, larger pretherapy tumor size, lower grade, lower clinical $\mathrm{T}$ and $\mathrm{N}$ stage, higher radiation dose, and delaying surgery by more than $6-8$ weeks after the end of radiation were independently associated with $\mathrm{pCR}$, while lack of health insurance was associated with a lower likelihood of pCR. Patients treated earlier in the study cohort were more likely to have pCR. A pCR 
was associated with a significant decrement in the number of nodes examined in the pathologic specimen compared with specimens with residual tumor (Table 2).

\section{Postoperative Morbidity}

In the propensity-adjusted analysis, the mean LOS was 0.23 days shorter in the $\mathrm{pCR}$ group $(p=0.045)$. Overall 30-day mortality was $0.7 \%$, and the unplanned readmission rate was $7.1 \%$. No difference in 30-day mortality or unplanned readmissions was observed between the two groups (Table 3).

\section{DISCUSSION}

\section{Predictors of $\mathrm{pCR}$}

Rates of pCR after neoadjuvant treatment for rectal cancer are highly variable in the literature, ranging from 0 to $30 \%$ or higher, depending on the population in question. ${ }^{17-36}$ In our national sample, $23.3 \%$ of non-metastatic rectal cancer patients treated with nCRT and radical surgery between 2006 and 2011 achieved a pCR, without significant differences being identified between facility locations on multivariable analysis. This represents an impressive fraction of treated cases and suggests appropriate application of standard techniques across cancer treatment centers nationwide.

We identified several clinicopathologic and treatment-related factors that were independently associated with pCR. Lower tumor grade, lower clinical $\mathrm{T}$ and $\mathrm{N}$ stage, higher radiation dose, and delaying surgery by more than 6-8 weeks after the end of radiation were associated with higher odds of $\mathrm{pCR}$, whereas lack of health insurance was linked with a lower likelihood of pCR. Numerous retrospective cohort studies have previously examined this question and have identified a variety of disease-related variables as potential predictors of pCR. These include low pre-therapy CEA, ${ }^{17,21,26,28,37,38}$ low CEA after nCRT, ${ }^{29,35}$ small pre- ${ }^{31,38}$ and post-treatment tumor size, ${ }^{22}$ pre-treatment tumor 'movability', ${ }^{22}$ low N category, ${ }^{31}$ low tumor grade, ${ }^{36}$ shorter distance from the anal verge, ${ }^{18,36}$ smaller circumferential tumor extent, ${ }^{18,28}$ and low neutrophil to lymphocyte ratio. ${ }^{38}$ Identification and awareness of these factors may help to predict which patients are more likely to achieve pCR with neoadjuvant treatment, and may be used to counsel patients more accurately regarding their prognosis and treatment options. It is interesting that several of these factors are also those that make a rectal tumor more suitable for transanal excision; ${ }^{39}$ thus, patients with tumors that exhibit most or all of these features may potentially be identified as safe candidates for less radical surgery following neoadjuvant therapy. ${ }^{9}$

Studies have also found a number of treatment-related variables that are associated with a higher likelihood of complete response, including the interval from the end of radiation to surgery, ${ }^{19,20,23,27,32,40-42}$ type of concurrent chemotherapy used, ${ }^{43}$ and radiation dose. ${ }^{44-46}$ In particular, the interval from the end of radiation to surgery has been of special interest and has been directly addressed by multiple studies as well as a meta-analysis. ${ }^{41}$ Although the exact ideal interval to optimize pCR has not been identified, the overall conclusion from these studies is that pCR rates improve with delaying surgery by more than 6-8 weeks after the end of nCRT. A recently published study using NCDB data provided the largest dataset 
focusing on the question of the interval from the end of nCRT to surgery, and concurred with the published literature that an interval of more than 8 weeks is associated with increased rates of complete response. ${ }^{42}$ Our results, which are derived from the same dataset, are consistent with those findings but, furthermore, offer additional variables that can help identify those patients most likely to respond.

There is an established relationship between radiation dose and achieving pCR, ${ }^{44-46}$ which was reflected in our own findings, that a higher radiation dose was associated with an increased likelihood of pCR. Current National Comprehensive Cancer Network (NCCN) guidelines for resectable tumors recommend a standard dose of $4500 \mathrm{cGy}$, with consideration for a tumor bed boost of $540 \mathrm{cGy} .{ }^{47} \mathrm{In}$ our study, more than $80 \%$ of patients were treated with a dose within this range. The use of progressively higher doses naturally raises concerns regarding treatment toxicity; however, a recent meta-analysis of 14 studies including 487 patients with locally advanced rectal cancer, all treated with doses of $\searrow 6000$ cGy, demonstrated acceptable early toxicity, with a pCR rate of $20.4 \%$ and a pooled estimate of $10.3 \%$ for grade 3 or higher toxicity. ${ }^{34}$ The application of intensity-modulated radiation therapy (IMRT), while not yet standard treatment, may help to reduce this toxicity further without compromising response rates. ${ }^{25,33,48-50}$ Similar to previous studies, we did not identify a lower likelihood of $\mathrm{pCR}$ in patients who received IMRT relative to standard external beam therapy.

A new finding of this study was that lack of health insurance independently predicted a lower likelihood of pCR. Lack of insurance is known to be associated with poorer outcomes for several cancer types, including rectal cancer, ${ }^{51-54}$ which may be related to disparities in access to comprehensive, guideline-based cancer services. However, it is important to remember that all patients in this study cohort received nCRT and radical surgery, regardless of insurance status, suggesting that other, unmeasured factors associated with a lack of insurance likely affect patient outcomes and response to treatment, beyond the issue of access. This reinforces the need to address gaps in the care and overall health of this vulnerable patient population.

Two unexpected findings resulted from our multivariable analysis. First, the likelihood of achieving pCR decreased over the course of the study period. One explanation for this finding is that a proportion of patients with a cCR may have been treated with transanal excision or non-operative management during the study period. Excluding these patients (who are more likely to have pCR on the final specimen) from the study population would result in skewing of the sample to include fewer patients with $\mathrm{pCR}$ over time. Other possible contributing factors include the administration of short-course radiotherapy or chemotherapy without radiotherapy as alternative neoadjuvant strategies for rectal cancer patients. However, among all patients treated with neoadjuvant therapy during the study period, only $2.1 \%$ received an abbreviated radiation dose ( $<3000 \mathrm{cGy})$ and only $3.9 \%$ received chemotherapy without radiotherapy, with no significant increase in either strategy over time. Thus, these factors are unlikely to explain the reduction in pCR in later years.

Skewing of the patient sample due to selection bias likely also explains the other surprising result of our analysis, namely that larger tumor size correlated with a higher likelihood of 
pCR, a finding that directly contradicts those of previous studies. ${ }^{22,31,38}$ We hypothesized that proportionately more of the smaller tumors were selected for transanal excision after nCRT and were excluded from the analysis if they had pCR, whereas those with residual disease went on to have definitive radical resection and were thus included in our patient cohort. This would make it seem as though smaller size correlates negatively with $\mathrm{pCR}$.

\section{Postoperative Morbidity}

There has been some controversy regarding the association between $\mathrm{PCR}$ and postoperative morbidity after nCRT. Horisberger et al. ${ }^{55}$ compared rectal cancer patients receiving nCRT with a concurrent capecitabine and irinotecan regimen by type of pathologic response (major vs. minor responders/non-responders) and found an association between major response to nCRT and anastomotic leak rate. Stelzmueller et al. ${ }^{56}$ found that tumor downstaging in the final specimen was associated with an increased risk of major postoperative complications. In addition, Maggiori et al. ${ }^{57}$ found the reverse to be true in a group of patients undergoing laparoscopic total mesorectal excision, with fewer major complications, less infectionrelated morbidity, lower clinical anastomotic leak rates, and shorter LOS in patients with pCR. On the other hand, Duldulao et al. ${ }^{58}$ and Berkel et al. ${ }^{59}$ found no significant difference in postoperative complications between patients with pCR compared with non-pCR patients.

Using LOS, 30-day mortality, and unplanned readmissions as surrogates for major postoperative complications, we found no significant differences between patients with pCR and those with residual tumor. Our propensity-adjusted analysis demonstrated a slightly longer LOS among patients with residual tumor relative to those with $\mathrm{pCR}$, but it is questionable whether this is of clinical relevance.

\section{Strengths and Limitations of the Study}

This study represents the largest published dataset to date examining predictors of $\mathrm{pCR}$ after nCRT in rectal cancer. The NCDB accounts for $70 \%$ of all newly diagnosed cases treated in the US during the study period. These data are derived from Commission on Cancer (COC)accredited facilities which are subject to national standards for maintenance of quality of cancer care. As such, they provide a robust reinforcement to the existing literature and a fairly accurate representation of national outcomes. It is possible that rectal cancer cases not represented in the NCDB (and therefore excluded from this study) may not meet national standards with respect to management of this disease, and may differ in the way they were treated. However, these cases are expected to comprise predominantly patients who did not receive neoadjuvant treatment before surgery, since receiving neoadjuvant treatment is itself a quality measure for care of locally advanced rectal cancer. As our study focused on patients who completed neoadjuvant treatment, our findings are likely valid for addressing the study question.

Limitations of this study include missing or unmeasured variables that may potentially be related to $\mathrm{pCR}$, including information on specific chemotherapy regimens. As noted earlier, the exclusion of patients treated with transanal excision or non-operative management is a source of potential bias. On the other hand, including such patients in the analysis would be problematic given the lack of nodal staging information for that subset of patients. 


\section{CONCLUSIONS}

Nearly one-quarter of rectal cancer patients undergoing surgical resection achieved a pCR following treatment with nCRT. pCR was not associated with an increased risk of major postoperative complications. Factors associated with $\mathrm{pCR}$ included lower tumor grade, lower clinical $\mathrm{T}$ and $\mathrm{N}$ stage, higher radiation dose, and delaying surgery by more than 6-8 weeks after the end of radiation, while lack of health insurance was linked with a lower likelihood of pCR. Awareness of these variables can be valuable in counseling patients regarding prognosis and treatment options.

\section{REFERENCES}

1. Maas M, Melemans PJ, Valentini V, et al. Long-term outcome in patients with a pathological complete response after chemoradiation for rectal cancer: a pooled analysis of individual patient data. Lancet Oncol. 2010; 11:835-44. [PubMed: 20692872]

2. Zorcolo L, Rosman AS, Restivo A, et al. Complete pathologic response after combined modality treatment for rectal cancer and long-term survival: a meta-analysis. Ann Surg Oncol. 2012; 19:2822-32. [PubMed: 22434243]

3. Yang TJ, Goodman KA. Predicting complete response: is there a role for non-operative management of rectal cancer? J Gastrointest Oncol. 2015; 6:241-6. [PubMed: 25830042]

4. Glynne-Jones R, Hughes R. Critical appraisal of the "wait and see" approach in rectal cancer for clinical complete responders after chemoradiation. Br J Surg. 2012; 99:897-909. [PubMed: 22539154]

5. Sabbaga J, Braghiroli MI, Hoff PM. Is surgery always necessary in rectal cancer? Oncology (Williston Park). 2014; 28:607-11. [PubMed: 25144282]

6. Habr-Gama A, Perez RO, Wynn G, Marks J, Kessler H, Gama-Rodrigues J. Complete clinical response after neoadjuvant chemoradiation therapy for distal rectal cancer: characterization of clinical and endoscopic findings for standardization. Dis Colon Rectum. 2010; 53:1692-8. [PubMed: 21178866]

7. Habr-Gama A, Perez RO, Nadalin W, et al. Operative versus nonoperative treatment for stage 0 distal rectal cancer following chemoradiation therapy: long-term results. Ann Surg. 2004; 240:7117. [PubMed: 15383798]

8. Maas M, Beets-Tan RG, Lambregts DM, et al. Wait-and-see policy for clinical complete responders after chemoradiation for rectal cancer. J Clin Oncol. 2011; 29:4633-40. [PubMed: 22067400]

9. Smith JD, Ruby JA, Goodman KA, et al. Nonoperative management of rectal cancer with complete clinical response after neoadjuvant therapy. Ann Surg. 2012; 256:965-72. [PubMed: 23154394]

10. Dalton RSJ, Velineni R, Osborne ME, et al. A single-centre experience of chemoradiotherapy for rectal cancer: is there potential for nonoperative management? Colorectal Dis. 2012; 14:567-71. [PubMed: 21831177]

11. Smith RK, Fry RD, Mahmoud NN, Carter Paulson E. Surveillance after neoadjuvant therapy in advanced rectal cancer with complete clinical response can have comparable outcomes to total mesorectal excision. Int J Colorectal Dis. 2015; 30:769-74. [PubMed: 25787162]

12. Hiotis SP, Weber SM, Cohen AM, et al. Assessing the predictive value of clinical complete response to neoadjuvant therapy for rectal cancer: an analysis of 488 patients. J Am Coll Surg. 2002; 194:131-5. [PubMed: 11848629]

13. Zmora O, Dasilva GM, Gurland B, et al. Does rectal wall tumor eradication with preoperative chemoradiation permit a change in the operative strategy? Dis Colon Rectum. 2004; 47:1607-12. [PubMed: 15540288]

14. Stipa F, Zernecke A, Moore HG, et al. Residual mesorectal lymph node involvement following neoadjuvant combined-modality therapy: rationale for radical resection? Ann Surg Oncol. 2004; 11:187-91. [PubMed: 14761922] 
15. Pucciarelli S, Capirci C, Emanuele U, et al. Relationship between pathologic T-stage and nodal metastasis after preoperative chemoradiotherapy for locally advanced rectal cancer. Ann Surg Oncol. 2005; 12:111-6. [PubMed: 15827790]

16. Yeo SG, Kim DY, Kim TH, et al. Pathologic complete response of primary tumor following preoperative chemoradiotherapy for locally advanced rectal cancer: long-term outcomes and prognostic significance of pathologic nodal status. Ann Surg. 2010; 252:998-1004. [PubMed: 21107110]

17. Yoon SM, Kim DY, Kim TH, et al. Clinical parameters predicting pathologic tumor response after preoperative chemoradiotherapy for rectal cancer. Int J Radiat Oncol Biol Phys. 2007; 69:1167-72. [PubMed: 17967307]

18. Das P, Skibber JM, Rodriguez-Bigas MA, et al. Predictors of tumor response and downstaging in patients who receive preoperative chemoradiation for rectal cancer. Cancer. 2007; 109:1750-5. [PubMed: 17387743]

19. Tulchinsky H, Shmueli E, Figer A, Klausner JM, Rabau M. An interval > 7 weeks between neoadjuvant therapy and surgery improves pathologic complete response and disease-free survival in patients with locally advanced rectal cancer. Ann Surg Oncol. 2008; 15:2661-7. [PubMed: 18389322]

20. Kalady MF, de Campos-Lobato LF, Stocchi L, et al. Predictive factors of pathologic complete response after neoadjuvant chemoradiation for rectal cancer. Ann Surg. 2009; 250:582-9. [PubMed: 19710605]

21. Lee JH, Kim SH, Kim JG, Cho HM, Shim BY. Preoperative chemoradiotherapy (CRT) followed by laparoscopic surgery for rectal cancer: predictors of the tumor response and the long-term oncologic outcomes. Int J Radiat Oncol Biol Phys. 2011; 81:431-8. [PubMed: 20732756]

22. Park $\mathrm{CH}$, Kim HV, Cho YB, et al. Predicting tumor response after preoperative chemoradiation using clinic parameters in rectal cancer. World J Gastroenterol. 2011; 17:5310-6. [PubMed: 22219601]

23. Wolthuis AM, Penninckx F, Haustermans K, et al. Impact of interval between neoadjuvant chemoradiotherapy and TME for locally advanced rectal cancer on pathologic response and oncologic outcome. Ann Surg Oncol. 2012; 19:2833-41. [PubMed: 22451236]

24. Choi CH, Kim WD, Lee SJ, Park WY. Clinical predictive factors of pathologic tumor response after preoperative chemoradio-therapy in rectal cancer. Radiat Oncol J. 2012; 30:99-107. [PubMed: 23170288]

25. Arbea L, Martinez-Monge R, Diaz-Gonzalez JA, et al. Four-week neoadjuvant intensity-modulated radiation therapy with concurrent capecitabine and oxaliplatin in locally advanced rectal cancer patients: a validation phase II trial. Int J Radiat Oncol Biol Phys. 2012; 83:587-93. [PubMed: 22079731]

26. Wallin U, Rothenberger D, Lowry A, Luepker R, Mellgren A. CEA: a predictor for pathologic complete response after neoadjuvant therapy for rectal cancer. Dis Colon Rectum. 2013; 56:85968. [PubMed: 23739192]

27. Sloothaak DA, Geijsen DE, van Leersum NJ, et al. Optimal time interval between neoadjuvant chemoradiotherapy and surgery for rectal cancer. Br J Surg. 2013; 100:933-9. [PubMed: 23536485]

28. Huh JW, Kim HR, Kim YJ. Clinical prediction of pathological complete response after preoperative chemoradiotherapy for rectal cancer. Dis Colon Rectum. 2013; 56:698-703. [PubMed: 23652742]

29. Yang KL, Yang SH, Liang WY, et al. Carcinoembryonic antigen (CEA) level, CEA ratio, and treatment outcome of rectal cancer patients receiving pre-operative chemoradiation and surgery. Radiat Oncol. 2013; 8:43. [PubMed: 23452434]

30. Russo AL, Ryan DP, Borger DR, et al. Mutational and clinical predictors of pathologic complete response in the treatment of locally advanced rectal cancer. J Gastrointest Cancer. 2014; 45:34-9. [PubMed: 24006244]

31. Garland ML, Vather R, Bunkley N, Pearse M, Bissett IP. Clinical tumor size and nodal status predict pathologic complete response following neoadjuvant chemoradiotherapy for rectal cancer. Int J Colorectal Dis. 2014; 29:301-7. [PubMed: 24420737] 
32. Zeng WG, Zhou ZX, Liang JW, et al. Impact of interval between neoadjuvant chemoradiotherapy and surgery for rectal cancer on surgical and oncologic outcome. J Surg Oncol. 2014; 110:463-7. [PubMed: 24889826]

33. Zhu J, Liu F, Gu W, et al. Concomitant boost IMRT-based neoadjuvant chemoradiotherapy for clinical stage II/III rectal adenocarcinoma: results of a phase II study. Radiat Oncol. 2014; 9:70. [PubMed: 24606870]

34. Burbach JP, den Harder AM, Intven M, van Vulpen M, Verkooijen HM, Reerink O. Impact of radiotherapy boost on pathological complete response in patient with locally advanced rectal cancer: a systematic review and meta-analysis. Radiother Oncol. 2014; 113:1-9. [PubMed: 25281582]

35. Kleiman A, Al-Khamis A, Farsi A, et al. Normalization of CEA levels post-neoadjuvant therapy is a strong predictor of pathologic complete response in rectal cancer. J Gastrointest Surg. 2015; 19:1106-12. [PubMed: 25859755]

36. Elmessiry MM, Abouelnagah GM, Elzeiny MM, et al. Predictors of tumor response to neoadjuvant chemoradiation in locally advanced rectal cancer Egyptian patients. Arch Clin Exp Surg. 2015; 4:21-8.

37. Park YA, Sohn SK, Seong J, et al. Serum CEA as a predictor for the response to preoperative chemoradiation in rectal cancer. J Surg Oncol. 2006; 93:145-50. [PubMed: 16425302]

38. Kim IY, You SH, Kim YW. Neutrophil-lymphocyte ratio predicts pathologic tumor response and survival after preoperative chemoradiation for rectal cancer. BMC Surg. 2014; 14:94. [PubMed: 25406793]

39. Monson JR, Weiser MR, Buie WD, et al. Standards Practice Task Force of the American Society of Colon and Rectal Surgeons. Practice parameters for the management of rectal cancer (revised). Dis Colon Rectum. 2013; 56:535-50. [PubMed: 23575392]

40. Evans J, Tait D, Swift I, et al. Timing of surgery following preoperative therapy in rectal cancer: the need for a prospective randomized trial? Dis Colon Rectum. 2011; 54:1251-9. [PubMed: 21904139]

41. Petrelli F, Sgroi G, Sarti E, Barni S. Increasing the interval between neoadjuvant chemoradiotherapy and surgery in rectal cancer: a meta-analysis of published studies. Ann Surg. 2013 doi: 10.1097/SLA.0000000000000368.

42. Probst CP, Becerra AZ, Aquina CT, et al. Extended intervals after neoadjuvant therapy in locally advanced rectal cancer: the key to improved tumor response and potential organ preservation. $\mathrm{J}$ Am Coll Surg. 2015; 221:430-40. [PubMed: 26206642]

43. Deng Y, Chi P, Lan P, et al. A multi-center randomized controlled trial of mFOLFOX6 with or without radiation in neoadjuvant treatment of local advanced rectal cancer (FOWARC study): preliminary results [abstract no. 3500]. J Clin Oncol. 2015; 33(15 Suppl)

44. Chan AK, Wong AO, Langevin J, et al. Preoperative chemotherapy and pelvic radiation for tethered or fixed rectal cancer: a phase II dose escalation study. Int J Radiat Oncol Biol Phys. 2000; 48:843-56. [PubMed: 11020583]

45. Overgaard M, Overgaard J, Sell A. Dose-resposne relationship for radiation therapy of recurrent, residual, and primarily inoperable colorectal cancer. Radiother Oncol. 1984:217-25. [PubMed: 6505258]

46. Wiltshire KL, Ward IG, Swallow C, et al. Preoperative radiation with concurrent chemotherapy for resectable rectal cancer: effect of dose escalation on pathologic complete response, local recurrence-free survival, disease-free survival, and overall survival. Int J Radiat Oncol Biol Phys. 2006; 64:709-16. [PubMed: 16242252]

47. National Comprehensive Cancer Network. [Accessed 30 June 2015] Rectal cancer. version 3.2015http://www.nccn.org/professionals/physician_gls/pdf/rectal.pdf

48. Parekh A, Truong MT, Pashtan I, et al. Acute gastrointestinal toxicity and tumor response with preoperative intensity modulated radiation therapy for rectal cancer. Gastrointest Cancer Res. 2013; 6:137-43. [PubMed: 24312687]

49. Jabbour SK, Patel S, Herman JM, et al. Intensity-modulated radiation therapy for rectal carcinoma can reduce treatment breaks and emergency department visits. Int J Surg Oncol. 2012; 2012:891067. [PubMed: 22934164] 
50. Samuelian JM, Callister MD, Ashman JB, Young-Fadok TM, Borad MJ, Gunderson LL. Reduced acute bowel toxicity in patients treated with intensity-modulated radiotherapy for rectal cancer. Int J Radiat Oncol Biol Phys. 2012; 82:1981-7. [PubMed: 21477938]

51. Rosenberg AR, Kroon L, Chen L, Li CI, Jones B. Insurance status and risk of cancer mortality among adolescents and young adults. Cancer. 2015; 121:1279-86. [PubMed: 25492559]

52. Niu X, Roche LM, Pawlish KS, Henry KA. Cancer survival disparities by health insurance status. Cancer Med. 2013; 2:403-11. [PubMed: 23930216]

53. Ayanian JZ, Kohler BA, Abe T, Epstein AM. The relation between health insurance coverage and clinical outcomes among women with breast cancer. N Engl J Med. 1993; 329:326-31. [PubMed: 8321261]

54. Robbins AS, Payluck AL, Fedewa SA, Chen AY, Ward EM. Insurance status, comorbidity level, and survival among colorectal cancer patients age 18 to 64 years in the National Cancer Data Base from 2003 to 2005. J Clin Oncol. 2009; 27:3627-33. [PubMed: 19470927]

55. Horisberger K, Hofheinz RD, Palma P, et al. Tumor response to neoadjuvant chemoradiation in rectal cancer: predictor for surgical morbidity? Int J Colorectal Dis. 2008; 23:257-64. [PubMed: 18071720]

56. Stelzmueller I, Zitt M, Aigner F, et al. Postoperative morbidity following chemoradiation for locally advanced low rectal cancer. J Gastrointest Surg. 2009; 13:657-67. [PubMed: 19082672]

57. Maggiori L, Bretagnol F, Aslam MI, et al. Does pathologic response of rectal cancer influence postoperative morbidity after neoadjuvant radiochemotherapy and total mesorectal excision? Surgery. 2014; 155:468-75. [PubMed: 24439750]

58. Duldulao MP, Lee W, Le M, et al. Surgical complication and pathologic complete response after neoadjuvant chemoradiation in locally advanced rectal cancer. Am Surg. 2011; 77:1281-5. [PubMed: 22127070]

59. Berkel AE, Woutersen DP, van der Palen J, Klaase JM. Prognostic factors for postoperative morbidity and tumor response after neoadjuvant chemoradiation followed by resection for rectal cancer. J Gastrointest Surg. 2014; 18:1648-57. [PubMed: 24939597] 
TABLE 1

Characteristics of the study cohort

\begin{tabular}{|c|c|c|c|c|}
\hline Variable & All (\%) & $\operatorname{pCR}(\%)$ & Residual tumor (\%) & $p$ value $^{a}$ \\
\hline Number of patients & 23,747 & $5512(23.3)$ & $18,235(76.8)$ & - \\
\hline \multicolumn{5}{|l|}{ Demographic factors } \\
\hline \multicolumn{5}{|l|}{ Age (years) } \\
\hline Mean/median/range & $60.0 / 60.0 / 18.0-90.0$ & $60.5 / 60.00 / 19.0-90.0$ & 59.8/60.0/18.0-90.0 & $<0.001$ \\
\hline \multicolumn{5}{|l|}{ Sex } \\
\hline Male & 62.2 & 24.3 & 75.7 & 0.031 \\
\hline Female & 37.8 & 25.5 & 74.5 & \\
\hline \multicolumn{5}{|l|}{ Race } \\
\hline White & 87.4 & 24.7 & 75.3 & 0.101 \\
\hline Black & 7.9 & 23.5 & 76.5 & \\
\hline Other & 4.7 & 26.8 & 73.2 & \\
\hline \multicolumn{5}{|l|}{ Insurance } \\
\hline Private & 52.4 & 25.2 & 74.8 & 0.090 \\
\hline Government & 42.8 & 24.5 & 75.5 & \\
\hline None & 4.8 & 21.9 & 78.1 & \\
\hline \multicolumn{5}{|l|}{ Setting } \\
\hline Metropolitan & 78.6 & 24.7 & 75.3 & 0.312 \\
\hline Urban & 18.6 & 25.4 & 74.6 & \\
\hline Rural & 2.8 & 23.4 & 76.6 & \\
\hline \multicolumn{5}{|l|}{ Comorbidities $^{b}$} \\
\hline 0 & 79.8 & 24.9 & 75.1 & 0.305 \\
\hline 1 & 16.3 & 23.7 & 76.3 & \\
\hline $2+$ & 3.8 & 25.5 & 74.5 & \\
\hline \multicolumn{5}{|l|}{ Disease factors } \\
\hline \multicolumn{5}{|l|}{ Year } \\
\hline 2006 & 12.9 & 31.9 & 68.1 & $<0.001$ \\
\hline 2007 & 15.0 & 30.4 & 69.6 & \\
\hline 2008 & 17.0 & 27.3 & 72.7 & \\
\hline 2009 & 17.9 & 25.2 & 74.8 & \\
\hline 2010 & 18.6 & 18.2 & 81.8 & \\
\hline 2011 & 18.6 & 18.8 & 81.2 & \\
\hline \multicolumn{5}{|l|}{ Grade } \\
\hline Well differentiated & 8.6 & 23.3 & 76.7 & $<0.001$ \\
\hline Moderately differentiated & 76.8 & 22.8 & 77.2 & \\
\hline Poorly differentiated & 13.4 & 19.6 & 80.4 & \\
\hline Undifferentiated & 1.2 & 14.4 & 85.6 & \\
\hline \multicolumn{5}{|l|}{ Pre-therapy tumor size $(\mathrm{cm})$} \\
\hline No tumor & 0.1 & 100.0 & 0 & $<0.001$ \\
\hline$<1$ & 4.7 & 9.4 & 90.6 & \\
\hline
\end{tabular}




\begin{tabular}{|c|c|c|c|c|}
\hline Variable & All (\%) & $\operatorname{pCR}(\%)$ & Residual tumor $(\%)$ & $p$ value ${ }^{a}$ \\
\hline $1-2$ & 10.9 & 11.8 & 88.3 & \\
\hline $2-3$ & 16.2 & 18.0 & 82.0 & \\
\hline $3-4$ & 18.5 & 24.5 & 75.5 & \\
\hline $4-5$ & 16.9 & 24.7 & 75.3 & \\
\hline $5+$ & 32.5 & 22.8 & 77.2 & \\
\hline \multicolumn{5}{|l|}{ Clinical TNM stage } \\
\hline 0 & 0.1 & 18.8 & 81.3 & $<0.001$ \\
\hline 1 & 9.1 & 23.7 & 76.3 & \\
\hline 2 & 44.5 & 25.9 & 74.1 & \\
\hline 3 & 46.3 & 24.0 & 76.0 & \\
\hline \multicolumn{5}{|l|}{ Clinical $\mathrm{T}$ category } \\
\hline 1 & 3.8 & 28.3 & 71.7 & $<0.001$ \\
\hline 2 & 10.6 & 26.4 & 73.6 & \\
\hline 3 & 78.7 & 24.9 & 75.1 & \\
\hline 4 & 6.8 & 17.9 & 82.1 & \\
\hline \multicolumn{5}{|l|}{ Clinical N category } \\
\hline 0 & 53.2 & 25.6 & 74.4 & $<0.001$ \\
\hline 1 & 41.4 & 25.0 & 75.0 & \\
\hline 2 & 5.3 & 17.9 & 82.1 & \\
\hline \multicolumn{5}{|l|}{ Pathologic T category } \\
\hline $0 / \mathrm{X}$ & 24.5 & 100 & 0 & - \\
\hline 1 & 6.3 & 0 & 100 & \\
\hline 2 & 24.8 & 0 & 100 & \\
\hline 3 & 40.8 & 0 & 100 & \\
\hline 4 & 3.5 & 0 & 100 & \\
\hline \multicolumn{5}{|c|}{ Pathologic N category } \\
\hline $0 / \mathrm{X}$ & 72.4 & 32.1 & 67.9 & $<0.001$ \\
\hline 1 & 19.3 & 6.7 & 93.3 & \\
\hline 2 & 8.3 & 2.7 & 97.3 & \\
\hline \multicolumn{5}{|c|}{ Number of nodes examined } \\
\hline Mean/median/range & $13.5 / 13.0 / 0.0-90.0$ & $12.5 / 12.0 / 0.0-90$ & 0 13.8/13.0/0.0-90.0 & $<0.001$ \\
\hline \multicolumn{5}{|l|}{ CEA } \\
\hline Negative & 57.2 & 26.7 & 73.3 & $<0.001$ \\
\hline Positive & 42.8 & 18.5 & 81.5 & \\
\hline \multicolumn{5}{|l|}{ Tumor deposits } \\
\hline Absent & 93.7 & 18.0 & 82.0 & $<0.001$ \\
\hline Present & 6.3 & 3.6 & 96.4 & \\
\hline \multicolumn{5}{|c|}{ Tumor regression grade } \\
\hline 0 & 32.6 & 70.3 & 29.7 & $<0.001$ \\
\hline 1 & 37.1 & 4.9 & 95.1 & \\
\hline 2 & 21.0 & 2.2 & 97.8 & \\
\hline 3 & 9.3 & 2.0 & 98.0 & \\
\hline
\end{tabular}




\begin{tabular}{|c|c|c|c|c|}
\hline Variable & All (\%) & pCR (\%) & Residual tumor (\%) & $p$ value ${ }^{a}$ \\
\hline \multicolumn{5}{|l|}{ LVI } \\
\hline Negative & 85.7 & 13.0 & 87.0 & \multirow[t]{2}{*}{$<0.001$} \\
\hline Positive & 14.3 & 2.5 & 97.5 & \\
\hline \multicolumn{5}{|l|}{ PNI } \\
\hline Negative & 89.8 & 17.3 & 82.7 & \multirow[t]{2}{*}{$<0.001$} \\
\hline Positive & 10.2 & 1.9 & 98.1 & \\
\hline \multicolumn{5}{|l|}{ Margin status } \\
\hline Negative & 94.5 & 74.4 & 25.6 & \multirow[t]{2}{*}{$<0.001$} \\
\hline Positive & 5.5 & 11.5 & 88.5 & \\
\hline \multicolumn{5}{|l|}{ Treatment factors } \\
\hline \multicolumn{5}{|l|}{ Facility type } \\
\hline $\mathrm{CCP}$ & 9.3 & 23.4 & 76.6 & \multirow[t]{3}{*}{0.008} \\
\hline $\mathrm{CCCP}$ & 54.4 & 25.5 & 74.5 & \\
\hline Academic & 36.4 & 24.0 & 76.0 & \\
\hline \multicolumn{5}{|l|}{ Surgery } \\
\hline Partial proctectomy & 58.5 & 25.5 & 74.5 & \multirow[t]{5}{*}{$<0.001$} \\
\hline Total proctectomy & 28.1 & 23.5 & 76.5 & \\
\hline Pull through & 8.3 & 25.8 & 74.2 & \\
\hline Total proctocolectomy & 2.4 & 24.7 & 75.3 & \\
\hline Pelvic exenteration & 2.7 & 18.8 & 81.2 & \\
\hline \multicolumn{5}{|l|}{ Surgical approach } \\
\hline MIS & 28.8 & 20.8 & 79.2 & \multirow[t]{2}{*}{0.036} \\
\hline Open/converted to open & 71.2 & 17.6 & 82.4 & \\
\hline \multicolumn{5}{|l|}{ Radiation modality } \\
\hline External beam & 73.5 & 25.0 & 75.0 & \multirow[t]{4}{*}{0.681} \\
\hline Conformal/3D & 14.8 & 24.1 & 75.9 & \\
\hline IMRT & 11.1 & 24.2 & 75.8 & \\
\hline Other & 0.5 & 22.8 & 77.2 & \\
\hline \multicolumn{5}{|l|}{ Radiation dose (cGy) } \\
\hline$<4500$ & 3.4 & 19.9 & 80.1 & \multirow[t]{4}{*}{0.024} \\
\hline $4500-5040$ & 81.2 & 25.2 & 74.8 & \\
\hline $5041-5400$ & 10.6 & 25.7 & 74.3 & \\
\hline$>5400$ & 4.8 & 26.4 & 73.6 & \\
\hline \multicolumn{5}{|c|}{$\begin{array}{l}\text { Interval from end of radiation } \\
\text { to surgery (weeks) }\end{array}$} \\
\hline$<6$ & 22.8 & 22.1 & 77.9 & \multirow[t]{5}{*}{0.088} \\
\hline $6-8$ & 36.7 & 24.3 & 75.7 & \\
\hline $8-10$ & 23.0 & 23.7 & 76.3 & \\
\hline $10-12$ & 8.7 & 23.6 & 76.4 & \\
\hline $12+$ & 8.7 & 23.3 & 76.7 & \\
\hline
\end{tabular}

$p C R$ pathologic complete response, $C E A$ carcinoembryonic antigen, $L V I$ lymphovascular invasion, $P N I$ perineural invasion, $3 D$ three-dimensional, IMRT intensity-modulated radiation therapy, $N C D B$ National Cancer Database

Ann Surg Oncol. Author manuscript; available in PMC 2017 February 07. 
${ }^{a}$ Univariable model

${ }^{b}$ Comorbidities are documented in the NCDB as the Charlson-Deyo comorbidity score 


\section{TABLE 2}

Factors associated with pCR (multivariable model)

\begin{tabular}{|c|c|c|}
\hline Variable & $\begin{array}{l}\text { Adjusted OR for pCR } \\
(95 \% \text { CI })\end{array}$ & $p$ value \\
\hline \multicolumn{3}{|l|}{ Insurance } \\
\hline Private & 1.0 & 0.001 \\
\hline Government & $0.98(0.89-1.08)$ & \\
\hline None & $0.64(0.50-0.81)$ & \\
\hline \multicolumn{3}{|l|}{ Year of diagnosis } \\
\hline 2006 & 1.0 & $<0.001$ \\
\hline 2007 & $0.95(0.81-1.11)$ & \\
\hline 2008 & $0.68(0.58-0.80)$ & \\
\hline 2009 & $0.67(0.57-0.78)$ & \\
\hline 2010 & $0.35(0.30-0.42)$ & \\
\hline 2011 & $0.38(0.32-0.45)$ & \\
\hline \multicolumn{3}{|l|}{ Grade } \\
\hline Well differentiated & 1.0 & 0.002 \\
\hline Moderately differentiated & $1.01(0.86-1.19)$ & \\
\hline Poorly differentiated & $0.78(0.63-0.96)$ & \\
\hline Undifferentiated & $0.73(0.46-1.17)$ & \\
\hline \multicolumn{3}{|l|}{ Pre-therapy tumor size $(\mathrm{cm})$} \\
\hline$<1$ & 1.0 & $<0.001$ \\
\hline $1-2$ & $1.22(0.87-1.71)$ & \\
\hline $2-3$ & $2.16(1.59-2.95)$ & \\
\hline $3-4$ & $3.16(2.33-4.29)$ & \\
\hline $4-5$ & $3.13(2.30-4.25)$ & \\
\hline$>5$ & $3.07(2.27-4.14)$ & \\
\hline \multicolumn{3}{|l|}{ Clinical $\mathrm{T}$ category } \\
\hline $\mathrm{T} 1$ & 1.0 & 0.002 \\
\hline $\mathrm{T} 2$ & $0.84(0.63-1.12)$ & \\
\hline $\mathrm{T} 3$ & $0.80(0.62-1.04)$ & \\
\hline $\mathrm{T} 4$ & $0.57(0.42-0.78)$ & \\
\hline \multicolumn{3}{|l|}{ Clinical N category } \\
\hline No & 1.0 & 0.014 \\
\hline N1 & $0.97(0.88-1.07)$ & \\
\hline $\mathrm{N} 2$ & $0.71(0.56-0.89)$ & \\
\hline \multicolumn{3}{|l|}{ Radiation dose (cGy) } \\
\hline$<4500$ & 1.0 & 0.015 \\
\hline $4500-5040$ & $1.40(1.06-1.85)$ & \\
\hline $5041-5400$ & $1.57(1.16-2.13)$ & \\
\hline$>5400$ & $1.63(1.16-2.28)$ & \\
\hline \multicolumn{3}{|l|}{ Interval to surgery (weeks) } \\
\hline$<6$ & 1.0 & 0.012 \\
\hline
\end{tabular}




\begin{tabular}{lll}
\hline Variable & $\begin{array}{l}\text { Adjusted OR for pCR } \\
\mathbf{9 5} \% \mathbf{C I})\end{array}$ & $\boldsymbol{p}$ value \\
\hline $6-8$ & $1.15(1.02-1.30)$ & \\
$8-10$ & $1.27(1.11-1.45)$ & \\
$10-12$ & $1.18(0.98-1.42)$ & \\
$>12$ & $1.25(1.03-1.51)$ & \\
Nodes examined & & \\
$\quad$ Per additional node & $0.99(0.98-0.99)$ & $<0.001$ \\
\hline
\end{tabular}

$p C R$ pathologic complete response, $O R$ odds ratio, $C I$ confidence interval 


\section{TABLE 3}

Postoperative course by response status (propensity-adjusted analysis)

\begin{tabular}{|c|c|c|c|c|c|c|c|}
\hline & pCR [mean & (SE)] & Res & dual tumor [mean (SE)] & Mean difference (SE) & $p$ value & \\
\hline \multirow[t]{2}{*}{ LOS, days } & $7.26(0.14)$ & & 7.49 & $(0.07)$ & $-0.23(0.15)$ & 0.045 & \\
\hline & & pCR & & Residual tumor (\%) & Adjusted OR $(95 \%$ CI $) \mathrm{p}$ & CR versus residual tumor & \\
\hline \multicolumn{2}{|c|}{ 30-day mortality } & 0.7 & & 0.7 & $0.61(0.33-1.14)$ & & 0.119 \\
\hline \multicolumn{2}{|c|}{ Unplanned readmissions } & 6.6 & & 7.3 & $0.90(0.75-1.08)$ & & 0.271 \\
\hline
\end{tabular}

$p C R$ pathologic complete response, $S E$ standard error, $L O S$ length of stay, $O R$ odds ratio, $C I$ confidence interval 